\title{
Prognosis of convulsions between 1 and 6 months of age
}

\author{
T O'BRIEN, R COUNAHAN, B O'BRIEN, AND J F COSGROVE
}

Regional Paediatric Unit, Ardkeen Hospital, Waterford, Ireland

SUMMARY The prognosis of 28 infants presenting consecutively to a general paediatric unit with convulsions between 1 and 6 months of age was far better than had been reported previously. Between 1 and 4 years after presentation the condition of 19 patients was normal, 3 were mildly handicapped, 4 severely handicapped, and 2 had died. Normal physical examination and electroencephalogram at time of presentation, and easy control of convulsions were associated with a satisfactory outcome.

With the exception of infantile spasms and neonat a meningitis, little is known about the natural history of convulsions occurring between 1 and 6 months of age. The prognosis has been reported to be poor. ${ }^{12}$ We examined retrospectively the course of 28 infants who had presented with a first confirmed convulsion between 1 and 6 months of age. The aims of the study were to determine their prognosis, and to decide if the eventual outcome could be predicted at initial presentation.

\section{Patients and methods}

The case notes of every child who had had a convulsion between 1 and 6 months of age and been admitted to the Regional Paediatric Unit at this hospital between September 1975 (when the unit opened) and June 1979 were studied. Only those who at some time had been seen to convulse by medical personnel, and who did not have a confirmed convulsion in the first month of life were analysed for the purpose of the study. Infants with a vague history of twitching were excluded. There were 28 infants in all (14 boys and 14 girls) and their clinical data and follow-up are given in the Table. They were assessed on follow-up according to the technique of Sheridan $^{3}$ by recall to outpatient clinics or at home. Public health developmental assessment records available for 13 of the children were also examined. Psychological (IQ) testing was not performed.

Results

Nineteen patients were normal on follow-up

Table Clinical presentation and follow-up of patients

\begin{tabular}{|c|c|c|c|c|c|c|c|c|c|c|}
\hline Case & Type & Duration & No & Time span & $\begin{array}{l}\text { Age at } \\
\text { onset } \\
\text { (months) }\end{array}$ & $\begin{array}{l}\text { Neurological } \\
\text { status at } \\
\text { presentation }\end{array}$ & $E E G$ & $\begin{array}{l}\text { Response to } \\
\text { treatment }\end{array}$ & Outcome & $\begin{array}{l}\text { Duration of } \\
\text { follow-up } \\
\text { (years) }\end{array}$ \\
\hline 1 & Generalised & $\frac{1}{2} \min$ & 10-12/day & 7 days & 1 & Abnormal & - & Poor & Handicap & $1 \cdot 5$ \\
\hline 2 & Generalised & $1 \mathrm{~min}$ & Several & 2 weeks & 1 & Normal & Abnormal & Good & Normal & $2 \cdot 4$ \\
\hline 3 & Generalised & $1-10 \mathrm{~min}$ & 5 & 1 day & 2 & Abnormal & Abnormal & Good & Normal & $1 \cdot 4$ \\
\hline 4 & Generalised & $5 \mathrm{~min}$ & 4 & 2 days & 2 & Normal & Normal & Good & Normal & $3 \cdot 25$ \\
\hline 5 & Generalised & $3 \mathrm{~min}$ & 4 & 1 day & 2 & Abnormal & Normal & Good & Normal & $1 \cdot 9$ \\
\hline 6 & Generalised & $2 \min$ & 6 & 1 day & $2 \cdot 5$ & Normal & - & Good & Normal & $3 \cdot 75$ \\
\hline 7 & Generalised & Short & 3 & 1 day & $2 \cdot 5$ & Normal & Equivocal & Good & Normal & $2 \cdot 4$ \\
\hline 8 & Generalised & $10 \mathrm{~min}$ & 5 & 1 day & $2 \cdot 5$ & Normal & Normal & Good & Normal & $1 \cdot 0$ \\
\hline 9 & Generalised & $2 \min$ & 3 & 2 days & $2 \cdot 5$ & Normal & Normal & Good & Normal & $1 \cdot 75$ \\
\hline 10 & Generalised & $1 \mathrm{~min}$ & 8 & 2 days & 3 & Normal & Normal & Good & Normal & $3 \cdot 0$ \\
\hline 11 & Generalised & $3-5 \mathrm{~min}$ & 4 & 1 day & 3 & Normal & - & Good & Normal & $1 \cdot 3$ \\
\hline 12 & Generalised & $2-3 \mathrm{~min}$ & 5 & 6 days & 3 & Abnormal & 一 & Good & Normal & $2 \cdot 3$ \\
\hline 13 & Generalised & $15-20 \mathrm{~min}$ & 1 & - & $3 \cdot 5$ & Normal & - & - & Normal & $2 \cdot 0$ \\
\hline 14 & Generalised & $20 \mathrm{~min}$ & Frequent & 19 days & $4 \cdot 5$ & Abnormal & Abnormal & Poor & Dead & $4 \cdot 1$ \\
\hline 15 & Generalised & $5 \mathrm{~min}$ & 1 & 一 & $4 \cdot 5$ & Normal & 一 & Good & Normal & $3 \cdot 0$ \\
\hline 16 & Generalised & $\frac{1}{2} \min$ & 6 & 1 day & $4 \cdot 5$ & Normal & Normal & Good & Normal & $3 \cdot 4$ \\
\hline 17 & Generalised & $2 \frac{1}{2}$ hours & 1 & - & 5 & Normal & - & Good & Normal & $3 \cdot 1$ \\
\hline 18 & Focal & $1-10 \mathrm{~min}$ & 8 & 2 days & 1 & Normal & Normal & Good & Normal & $1 \cdot 8$ \\
\hline 19 & Focal & $5 \mathrm{~min}$ & 6 & 1 day & $2 \cdot 5$ & Normal & Normal & Good & Normal & $1 \cdot 5$ \\
\hline 20 & Focal & $\frac{1}{2} \min$ & $>10 /$ day & 2-3 days & $2 \cdot 5$ & Abnormal & 一 & Good & Handicap & $1 \cdot 5$ \\
\hline 21 & Multifocal & 15 seconds & Several & 10 days & $3 \cdot 5$ & Normal & 一 & - & Normal & $3 \cdot 8$ \\
\hline 22 & Multifocal & Brief & Several/day & 4 days & $3 \cdot 5$ & Abnormal & Abnormal & Good & Handicap & $1 \cdot 5$ \\
\hline 23 & Mixed & $2 \mathrm{~min}$ & 5 & 6 weeks & $1 \cdot 5$ & Normal & Normal & Good & Normal & $3 \cdot 2$ \\
\hline 24 & Mixed & $1 \mathrm{~min}$ & 2 & 10 days & 4 & Abnormal & Normal & Poor & Handicap & $1 \cdot 2$ \\
\hline 25 & Mycoclonic & Brief & Frequent & 5 days & $5 \cdot 5$ & Abnormal & Abnormal & Poor & Handicap & $3 \cdot 0$ \\
\hline 26 & Infantile spasms & Brief & Frequent & 2 weeks & $1 \cdot 5$ & Abnormal & Abnormal & Poor & Dead & $3 \cdot 9$ \\
\hline 27 & Infantile spasms & Brief & Frequent & 2 weeks & 2 & Abnormal & Abnormal & Poor & Handicap & $3 \cdot 5$ \\
\hline 28 & Infantile spasms & Brief & Frequent & 5 days & 5 & Abnormal & Abnormal & Good & Handicap & $3 \cdot 2$ \\
\hline
\end{tabular}


examination. Three patients were slightly handicapped: one (Case 28) had delayed speech development, another (Case 23) with recurrent convulsions started to fail to reach milestones at age 18 months having previously progressed normally, and the third (Case 22) who appeared to be normal developmentally at 13 months of age had slowed by 22 months. Four patients (Cases 1, 20, 25, and 27) were severely handicapped. Two patients (Cases 14 and 26) had died, one at age 23 months and the other at 14 months.

Predisposing factors for convulsions. Three patients (Cases 9, 13, and 15) had associated fever. Two (Cases 5 and 21) had a family history of epilepsy and 1 (Case 16) had a sibling with cerebral palsy. Two patients had concurrent meningitis-1 bacterial (Case 20) and 1 viral (Case 1). One patient (Case 22) presented with an acute encephalopathic illness, and myoclonic epilepsy began after an acute collapse in infancy in another with congenital heart disease (Case 25). One patient (Case 17) had received excessive intrathecal penicillin at another hospital. Of the patients who died one (Case 14) had microcephaly, and the other (Case 26) had a progressive undefined degenerative brain disease and an examination at necropsy was not possible.

There were certain features distinguishing the subsequently normal from the handicapped.

\section{Neurological status at presentation}

Of 19 clinically normal patients, 16 were neurologically normal at presentation. One of the 3 remaining patients (Case 2) had occasional twitching, another (Case 3) showed some fisting, and the third (Case 12) had slight head lag and prominent Moro and grasp reflexes at age $4 \frac{1}{2}$ months. All 9 handicapped patients were neurologically abnormal at presentation.

\section{Electroencephalograms}

Electroencephalogram (EEG) reports were available on 12 of 19 normal children. Two were abnormal and 1 was equivocal. One of 7 handicapped children had a normal EEG during the ensuing months despite having repeated convulsions. One handicapped child whose illness began as neonatal viral meningitis did not have an EEG. Both patients who died had abnormal EEGs.

\section{Response to therapy}

The majority of normal patients were treated with single anticonvulsants, generally phenobarbitone, and were easily controlled. Three were not maintained on anticonvulsants. None was treated for longer than 1 year. Anticonvulsants controlled well the convulsions of 3 of 7 handicapped children but did not control either of the 2 patients who died. Three patients had infantile spasms. Two were handicapped and one subsequently died. The third responded well to adrenocorticotrophic hormone, subsequently had recurrent grand mal convulsions which ultimately settled, and now is mildly mentally handicapped and fit-free.

Blood sugar and plasma calcium concentrations, antibody titres to rubella, toxoplasmosis, and cytomegalovirus, urine amino-acid chromatography, and skull $x$-rays films were not of any discriminatory value. Both in normal and retarded children perinatal history and birthweight were similar. No child had had triple vaccination in the month preceding admission.

\section{Discussion}

In a series of 20 infants with partial seizures between 1 and 3 months of age, followed prospectively by $\mathrm{O}^{\prime} \mathrm{Donohoe}^{2}$ for 8 years, only 4 were mentally normal. Chevrie and Aicardi ${ }^{1}$ found only 65 of 313 patients with convulsions between 1 and 12 months of age, excluding those with febrile convulsions and acute cerebral insults, to be mentally normal when followed for periods ranging from 1 to 24 years. Forty-one $(13 \%)$ of an initial study group of 334 patients had died. The prognosis for normal mental development was even worse in the 1- to 6-month age group. In contrast only $9(32 \%)$ patients in our study were retarded, or had died. If the 3 patients with infantile spasms are excluded, $76 \%$ of the remaining 25 patients developed normally.

We feel that the difference between this report and other studies is largely due to patient selection. Those quoted were from paediatric neurologists, who would be expected to have had specific neurological referrals, whereas our series came from a general paediatric service with referrals mainly from family doctors. The effect on selection by referral was shown by Chevrie and Aicardi ${ }^{4}$ who reported twice as many non-febrile convulsions between 1 and 6 months of age as febrile convulsions under 1 year of age. The reverse is true at this hospital. Similarly, Rossiter et $\mathrm{al} .{ }^{5}$ who prospectively studied a cohort of nearly 6000 newborn infants, reported that of the $91 \%$ successfully followed, 58 had febrile convulsions and 20 had non-febrile convulsions under age 1 year. Chevrie and Aicardi ${ }^{4}$ acknowledged selection in noting unexpectedly more girls than boys with febrile convulsions under 1 year of age. We referred 4 of the eventually retarded and only 1 of the normal patients for paediatric neurological opinion. If all general paediatric units had a similar referral pattern, the neurologist would find the majority of such a group to be retarded on follow-up. 
Neither physical examination nor the EEG discriminated clearly between the two groups on follow-up. Only 1 normal patient had abnormal physical signs and an abnormal EEG on presentation, whereas 6 of 9 patients in the poor outcome group had both abnormal physical signs and abnormal EEGs, and all 9 had abnormal neurological signs. The abnormal signs in 3 patients in the good outcome group were only briefly sustained. A good response to treatment clearly differentiated those with a good from those with a bad outcome. Rose and Lombroso $^{6}$ reported that the EEG was of prognostic value in neonatal seizures. They found that $86 \%$ of infants with neonatal seizures and a normal interictal EEG developed normally, while only $12 \%$ of those with multifocal abnormality on EEG were subsequently normal.

We concluded from our small study that, in a general paediatric practice, the prognosis of convulsions occurring between 1 and 6 months of age was considerably better than had been thought. Provided physical examination and EEG were normal, and the convulsions easily controlled, a good outlook might be expected.
We thank Dr P F Deasy and Dr N V O'Donohoe for constructive criticism, Public Health Staff for making records available, and Miss Mary Lannon for secretarial assistance.

\section{References \\ 1 Chevrie J J, Aicardi J. Convulsive disorders in the first year of life: neurological and mental outcome and mortality. Epilepsia 1978; 19 : 67-74. \\ 2 O'Donohoe N V. Convulsions in early infancy and infantile spasms. In: Epilepsies in childhood. London: Butterworth, 1979: 30-48. \\ 3 Sheridan M D. Children's developmental progress from birth to five years, third edition. Windsor: NEFR Pub- lishing Company, 1975. \\ 4 Chevrie J J, Aicardi J. Convulsive disorders in the first year of life: etiologic factors. Epilepsia 1977; 18: 489-97. \\ 5 Rossiter E J R, Luckin J, Vile A, Ganly N, Hallowes R, Pearson R D. Convulsions in the first three years of life. Med J Aust 1977; ii: 735-40. \\ - Rose A L, Lombroso C T. Neonatal seizure states. Pediatrics 1970; 45: 404-25.}

Correspondence to $\operatorname{Dr} \mathrm{R}$ Counahan, Paediatric Unit, Ardkeen Hospital, Waterford, Ireland.

Received 23 February 1981

\title{
Bradycardia and associated respiratory changes in neonates
}

\author{
M L SMITH AND A D MILNER \\ Department of Neonatal Medicine and Surgery, City Hospital, Nottingham
}

SUMMARY Electrocardiogram and patterns of respiration were recorded continuously in 9 newborn infants having episodes of bradycardia. The episodes were not associated with demonstrable apnoea, either by using an apnoea mattress or by visual observation. The 'non-apnoea' associated bradycardia was always associated with changes in respiratory pattern, of which three different forms could be identified. These were prolonged apnoea if the apnoea alarm failed to trigger, short episodes of respiratory abnormalities associated with body movement (possibly in rapid eye movement sleep), and minor changes in respiratory pattern. It may be appropriate to incorporate a period of delay in heart rate monitoring systems before the alarm sounds, in a similar manner to apnoea alarm systems. We should rely more on heart rate in conjunction with apnoea alarms to detect problems, or produce better systems which detect respiratory flow.

The advent of intensive neonatal care has necessitated an increase in the monitoring of many physiological parameters including heart rate and respiratory activity. Apnoea and associated cardiovascular changes have been widely investigated in preterm babies. However, we have been aware that many bradycardias occur without obvious associated respiratory change being noted by nursing or medical attendants. The object of this study was to investigate whether these heart rate changes in preterm babies were isolated events or accompanied by changes in respiratory activity.

\section{Method and definitions}

The babies were studied in the prone and supine positions using the respiratory jacket previously described by Milner ${ }^{1}$ while nursed in incubators on thermister apnoea mattresses ${ }^{2}$ (Vickers Medical). Respiratory pattern and electrocardiogram (ECG) were recorded simultaneously on heat-sensitive paper, using a Devices 2-channel recorder (M2R) and preamplifier (M2P). The jacket was inflated to a pressure of 4 to $5 \mathrm{cmH}_{2} \mathrm{O}(0.4-0.5 \mathrm{kPa})$ and any pressure change was recorded by a pressure 